\title{
Students Talk About Their HIV/AIDS Education Courses: A Case Of Addis Ababa, Ethiopia
}

Mariam M. Sambe, Concordia University, Canada

\begin{abstract}
The objective of this research was to explore how Ethiopian high school students experienced the HIVIAIDS education programs offered in their schools. The project also examined gender differences in the way HIV/AIDS education was perceived and the implications for the instructional design of the programs. A total of 15 high school students (eight females and seven males between the ages of 13 and 18) in Addis Ababa, the capital of Ethiopia, were recruited through purposeful sampling. Data were collected using two focus groups with each group comprising one gender. This separation of genders was ideal to enable participants to express their thoughts freely and to observe possible gender divergences.
\end{abstract}

Findings: All participants agreed that school-based HIV/AIDS education was essential but that unfortunately, most of the programs that students attended were neither interesting nor beneficial. Gender differences were observed with females asking for in-school AIDS education to completely modify its focus and males feeling that the education's current strategies should simply be improved. The implications of these results are discussed along with recommendations for further research.

Keywords: Exploratory Study; AIDS Education; Ethiopian Students; Secondary School

\section{INTRODUCTION}

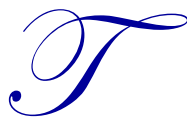

o promote HIV/AIDS prevention, school-based education has become one of the priorities on which to focus. In Sub-Saharan Africa (SSA), more than half of the population is in the primary or secondary school level (Jacob, Mosman, Hite, Morisky, \& Nsubuga, 2007); therefore, the best way to reach youth is to conduct in-school education. Several surveys illustrate that the educational system is among the most important vehicles used to disseminate HIV/AIDS knowledge (Kelly, 2000; Jacob, Morisky, Hite \& Nsubuga, 2006; Jacob, Shaw, Morisky, Hite, \& Nsubuga, 2007). Because health facilities are difficult to reach in SSA, it is easier for students to learn the information they need at school (Kaaya, Mukoma, Flisher, \& Klepp, 2002). Unfortunately, numerous schools struggle to develop effective HIV/AIDS instruction programs (Jacob et al., 2007). In these cases, the education that the students receive fails to promote behavioural change regarding HIV/AIDS prevention.

Since the early 1990s, Ethiopia has developed varied HIV and AIDS education programs (National Hiv/Aids Prevention And Control Office [HAPCO], 2007). One city that is greatly benefiting from this education is the capital, Addis Ababa. Yet, it has one of the highest HIV prevalence rates in the country (Federal Ministry Of Health, 2007). Although the rise of in-school HIV/AIDS programs has helped spread awareness, students' behaviour toward HIV prevention still has a long way to go. Ethiopia remains at risk of remaining a dreadful target for HIV/AIDS with its 1.5 million people living with HIV (Tamene \& Fantahun, 2007). Thus, the question that warrants investigation is, "To what extent are the HIV/AIDS instructional methods relevant to students' needs and interests?"

When considering what students need, it is first crucial to study their level of awareness about HIV/AIDS. Research conducted in rural areas of Ethiopia showed that only $44 \%$ of adolescent boys and $41 \%$ of adolescent girls had accurate knowledge of HIV and how it was transmitted (Alene, Wheeler, \& Grosskurth, 2004). The awareness level is different in urban areas where great majorities of youth know about HIV/AIDS, its transmission, and how to be 
protected. Indeed, in its 2005 study, the Demographic Health Survey (DHS) showed that $97 \%$ of males and $90 \%$ of females between 15 to 49 years old had a clear understanding of HIV/AIDS (HAPCO, 2008). Hence, in Ethiopia-just as in most other African countries - awareness continues to grow. In fact, several research studies illustrate that some behaviour change can also be observed (UNAIDS, 2008). The gap between HIV/AIDS awareness and people's behaviour in protecting themselves is thus slowly shrinking. Despite this, the epidemic continues to exceed the response. This is partially because prevention strategies are not in parallel with where the greatest needs are. In other words, the key drivers of the epidemic are not well responded to (UNAIDS, 2009). Hence, examining groups that are at high risk — such as youth in urban cities—should be a priority.

While awareness is growing, some researchers are worried about the comprehensive knowledge of HIV/AIDS among the youth. The DHS study of 2005 illustrated that among people between 15 and 24 years old, only $33.3 \%$ of young males and $20 \%$ of young females had comprehensive knowledge of HIV/AIDS (HAPCO, 2008). General awareness is high, but there seems to be a lack of deep comprehensive knowledge, meaning that the details about how exactly HIV is transferable is lacking. Nonetheless, other researchers believe that even when it comes to comprehensive knowledge about AIDS, youth in urban areas are well informed. Now the issue is transferring that awareness to behavioural change. In other words, "the walk the talk" factor is missing. A study conducted in 2009 confirmed this. Of the 30 young Ethiopians were interviewed, 29 had a thorough understanding of HIV/AIDS (SAMBE, 2009). They knew about HIV symptoms, how it was transmitted, and how to avoid becoming infected. In spite of this, the anonymous survey conducted in that same research project discovered that only $60 \%$ of young Ethiopians used condoms consistently. Although youth were all well informed about HIV transmission, many were not behaving in a way that would reduce infection (Sambe, 2009). Similarly, research conducted by Fetene And Dimitriadis (2010) illustrated that knowledge about HIV/AIDS and safer sex practices is widespread among young Ethiopians, but this awareness does not always lead to actual behavioural changes. Of course, stigma and discrimination can also be factors that reduce the success of HIV/AIDS education. The shame associated with having AIDS or the stigma associated with premarital sex reduces the likelihood that people will get tested, talk about it, or seek help (Molla, Emmelin, Berhane, \& Lindtjørn, 2009).

One of the key reasons why HIV/AIDS education fails in many schools is the lack of evaluation. Indeed, evaluation should be an integral component of any in-school HIV/AIDS education program (Kaya et al., 2002). However, despite that risky sexual behaviours are observed in SSA, there are relatively few evaluations that examine how HIV/AIDS school-based interventions affect behavioural change (Kaya et al., 2002). The Ethiopian Ministry of Health and the Ministry of Education have put large amount of resources toward HIV/AIDS school education. However, there is a lack of monitoring and assessment of the programs implemented (Kloos, \& Haile Mariam, 2000). First, many anti-AIDS education programs are not incorporated into the curriculum and there is no formal teacher training designed to help teachers deliver these programs. Indeed, sexuality is a controversial subject that many teachers are unwilling to address (Kinsman et al., 1999; Oshi, Nakalema, \& Oshi, 2005). Unfortunately, there is a lack of research investigating how teachers address this and how that can affect the implementation of HIV/AIDS program in their curriculum (Mathews, Boon, Flisher, \& Schaalma, 2006). According to Hyde, Ekatan, Kiage and Barasa (2001), it is crucial to improve the skills of teachers to deliver HIV/AIDS education in curricula. This could help students receive the proper knowledge and skills needed to reduce HIV infection. In most African countries, schools actually depend on invited guests or outreach — rather than on schoolteachers - to give HIV/AIDS education (Hyde et al., 2001). However, it is important to note that when teachers receive formal training in HIV/AIDS education, they are often willing to implement it in their curricula (Mathews et al., 2006). Teacher training is therefore vital.

Another issue related to this lack of evaluation and what hinders the implementation of proper HIV/AIDS education is the limited amount of research on HIV/AIDS education strategies. Some countries, such as South Africa or Uganda, have better data. However, unlike these nations, which have also severely suffered from the HIV/AIDS pandemic, Ethiopia has a limited amount of data available on HIV/AIDS prevention research, especially related to youth in small towns or rural areas (Alene et al., 2004). This makes it difficult to build proper assessments and to compare and contrast trends between urban areas and rural ones. The HIV/AIDS epidemic in Ethiopia continues to spread among youth. However, few studies have been conducted to deliver the data needed to plan and put efficient HIV/AIDS education into operation for Ethiopian adolescents (Alene et al., 2004). The current study presents results from focus groups that were conducted with Ethiopian adolescents on their perceptions concerning HIV/AIDS education programs in their schools. 


\section{METHOD}

\section{Research Design}

This research project was an exploratory single case study design that provided a wealth of information on participants' perceptions about HIV/AIDS education in their schools. Students are directly affected by the HIV/AIDS instructions they receive yet, unfortunately, they have little opportunity to comment on the programs. Performing a case study design for this project was therefore valuable, as it is a strategy that offers the possibility to learn about the personal perspective of participants.

Two focus groups were conducted - one with females and one with males. This separation was ideal to enable participants to express their thoughts freely and for the researcher to observe possible gender differences. In addition to providing in-depth understanding, focus groups have the advantage of promoting a group's shared understanding of a phenomenon. This was highly beneficial for this project because the objective was to discover the collective opinions high school students in Addis Ababa have concerning the HIV/AIDS education programs of their schools.

\section{Study Area And Participants}

This research was conducted in Addis Ababa, the capital of Ethiopia and one of the hardest hit cities by the AIDS epidemic. The HIV prevalence rate in this city is estimated to be $15 \%$ (Fetene \& Dimitriadis, 2010). This metropolis is known to have a large sex industry, which increases the risk of infection. In fact, Aklilu et al. (2001) illustrated that HIV infection in Addis Ababa was as high as $74 \%$ among sex workers. To make matters worse, Addis Ababa is known for its massive youth migration due to its large number of universities, colleges, and job opportunities. Hence, the youth population that arrives in the city becomes at risk as well. As such, conducting research in the context of HIV/AIDS is essential in Addis Ababa.

Fifteen students (seven boys and eight girls) ages 13 through 18 were recruited through purposeful sampling. The sample was comprised of students from different social classes, ethnicities, schools (public, private, parochial, and international schools) and grades (from eighth to twelfth). This maximum variation technique was used in this study to compensate for the small sample size. Most importantly, it gave the opportunity to see whether students who come from different backgrounds have similar opinions about HIV/AIDS education programs. Maximum variation brings participants with varied types of experiences to talk about one topic of interest that they share. In the case of this project, the purpose was to understand how in-school HIV/AIDS education was perceived among different students in different settings. Hence, the selected participants gave detailed responses to the research question, "To what extent are the HIV/AIDS instructional methods pertinent to students' needs and/or interests?" Furthermore, whether a gender discrepancy exists in the way youths perceive HIV/AIDS was adequately observed. The purpose was to analyse the perceptions that participants have regarding the HIV/AIDS education they received.

\section{Data Collection Procedure}

\section{Prior To The Focus Group Sessions}

Two research assistants distributed flyers and information letters near selected high schools (on the street) as students left their schools. The flyers explained the purpose of the study and invited students to participate in a focus group. Prospective students signed a consent form if they were 18 years old and an assent form if they were younger than 17 years old (parents' consent form was also required for these participants). Students who responded and qualified for the focus group were recruited to participate. They were asked to choose a pseudonym that was used in place of their names to preserve confidentiality.

\section{During The Focus Group Sessions}

As the sole researcher for this project, the author facilitated both focus group interviews. The two focus groups were conducted separately - the first one with the seven male participants and the second one with the eight female participants. For each question asked, participants were given time to write down their answers on a piece of 
paper that they placed in the middle of the table. Then, step-by-step, each student explained what he or she had written, and other students were encouraged to comment or add further details.

\section{Ethical Consideration}

Approval was obtained from the Human Research Ethics Committee at Concordia University (Certificate number: 30000593). All participants and parents were informed of the purpose, benefits, and possible risks associated with the study, and both groups were told that participants could discontinue the interview at any time. A verbal and written informed consent was obtained from each study participant who was 18 years old. For participants who were younger, consent forms from their parents and assent forms from the participants were obtained. In addition, permission from the gatekeeper at the research site was gained a week prior to the focus groups. The gatekeeper was informed of the purpose of the research and gave written permission for the focus groups to be held at the selected research site - Kera area, Addis Ababa, Ethiopia.

\section{DATA ANALYSIS}

Prior to analysing the data, the researcher listened to the audio content of the focus group three times to gain a grasp of the themes that came out. Then the researcher transcribed the audio and field notes in their original language Amharic. After reading the content of the transcribed version twice, the researcher translated it into English, and it was ready for analysis. The researcher used the HyperRESEARCH program to conduct the analysis processes. HyperRESEARCH is a renowned computer program that allows for coding, retrieving, and conducting of qualitative data analysis (HYPERRESEARCH, 2013). The researcher created two cases (one for the male participants and the other for the female). Each case was coded separately to clearly see whether gender differences existed. The preliminary coding was done through the recurrent topics that were stated in the focus groups - 50 codes for the male participants and 47 codes for the females were first recorded. About half of these codes were in-vivo coding. Then, overlaps and redundancies were examined, which resulted in 16 codes for the boys' group and 15 for the girls. Finally, the codes were filtered by names and then collapsed into five themes per group. Table 1 illustrates this coding process.

The coding process was conducted with the research questions in mind to ensure accuracy and thoroughness: 1) According to students, to what extent are the HIV/AIDS instructional methods pertinent to their needs and/or interests? 2) Are there gender discrepancies in the way students perceive HIV/AIDS education, and if so, what are the implications for educational strategies?

To address qualitative rigor, the researcher got in contact with an external auditor who examined the raw data (transcribed and translated version of both focus groups) and the coding sheet for comparison and contrast purposes. In addition, once the study was complete, the researcher contacted two members from the focus groups (one male and one female) to ask them to review the raw data and the findings. This is the procedure of member checking. The external auditing and member checking techniques were crucial in this exploratory single case study as they confirmed that the researcher accurately formulated the participants' opinions and that the data were correctly decoded. Both the external auditor and the two participants who checked the raw data and findings approved of the results.

\section{FINDINGS}

All participants had extensive knowledge about HIV/AIDS and were eager to express their thoughts. They were familiar and had experience with the topic. They knew all about the prevention methods available. The discussions in both the female and male groups were lively and opinions were shared freely. The females respected their time and mostly spoke when it was their turn. They all had much to say and were very thorough in their answers, often giving examples and anecdotes. The male participants were a bit more casual and spoke whenever they had an idea or an opinion (not necessarily by turn). They still respected each other and raised their hands before answering. Just as with the girls, the boys also had a lot to say and used every opportunity possible to make their points. They gave several concrete examples based on their experiences.

The coding process was linked to the research questions of this study. Tables 1 and 2 illustrate the procedure that was taken. They present the coding schemes and the themes that emanated from the participants' answers. Both 
female and male groups shared the first four themes - 'saturation' (indirect education is needed), 'gap between teachers and students' preference', 'student-to-student education' and 'role of parents'. However, there was a divergence in the last themes - 'The media technique' for males and 'drugs and alcohol issues' for females. The codes (Table 2) and themes (Table 3) illustrate the main findings with respect to the research questions.

Coding Procedure: Step 1

Table 1: Coding Process

\begin{tabular}{|c|c|c|c|}
\hline Gender & Preliminary Codes & Similar Codes Grouped & Themes \\
\hline Males & 50 & 16 & 5 \\
\hline Females & 47 & 15 & 5 \\
\hline
\end{tabular}

Coding Procedure: Step 2

Table 2: Coding Scheme Developed From Raw Data (Similar Codes Grouped)

- AIDS education effect

- Drugs and alcohol to blame

- Education by students

- New generation of youth

- Saturation-boredom with AIDS education

- Denial about sex

- Teachers' and students' preference difference

- Outside organizations

- Entertainment education

- Gender difference

- Parents involvement

- Public vs. private school

- Media AIDS education

- Indirect education of AIDS

- Government involvement

- Innovative tools

Coding Procedure: Step 3

Table 3: Five Key Themes Identified Based On The Two Research Questions Of This Study

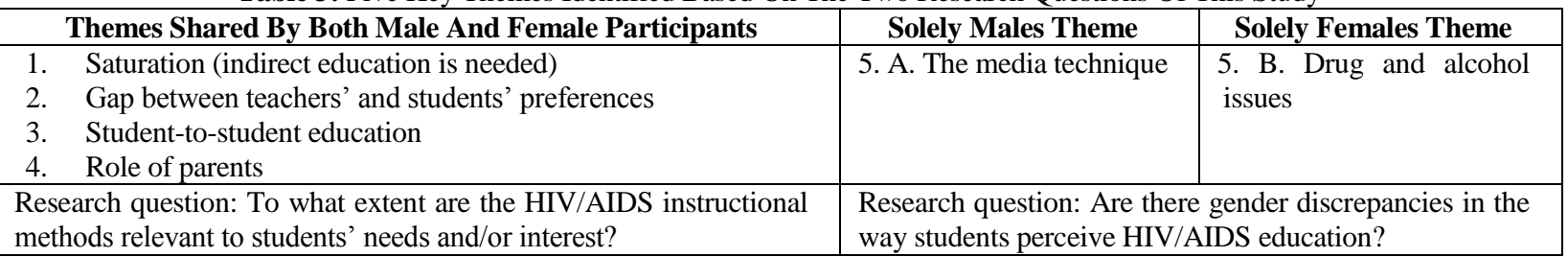

\section{Shared Experience About In-School HIV/AIDS Education}

\section{Theme 1: Saturation}

A recurrent theme in both groups was that HIV/AIDS education was viewed as boring and repetitive. Students stated that they often had little interest in attending HIV/AIDS courses because they were too monotonous and the classes offered no new information. The students clearly felt they had reached the point of saturation. For instance, Solomon stated, "In the classroom, we are sick to hear about AIDS. It is just the same thing over and over again." Mekonin, another male participant, went as far as saying that many students boycotted or skipped HIV/AIDS education altogether. He said, "We have other more important courses, you know? Like math or chemistry, where we actually learn something new. So we'd rather go to those classes when we have the chance." 
One of the reasons students found HIV/AIDS programs boring is because they lacked innovation. It is important to note that these participants have been hearing messages about HIV/AIDS prevention on a daily basis since they were born. These do not only come from school but also from the media, which use every possible opportunity to mention AIDS. Biniam (male) stated, "Me personally, I am sick of hearing about AIDS. If schools want me to focus on their HIV/AIDS education programs, then they need to find new tools and new means that are not boring."

On the girls' side, Helen said:

Since I was a kid, nothing has changed about AIDS. There is still no cure and the best way to prevent it is still abstinence or using condoms. So what's the point of telling me that over and over again? Clearly, that's not helping much since Ethiopia is still one of the countries with the highest infections in the world. Despite all the education we get, we are still getting infected. . I think we need indirect education. Stop talking about AIDS all the time but rather of things that would make us avoid getting infected. For example, if I live in an area that has too much drugs or violence, I have a higher chance of being infected by AIDS, so maybe schools can teach me how to overcome this lifestyle or how to get out of it. This way, I will be safe from HIV.

All other participants in the group shared Helen's point of view. They all agreed that indirect education was extremely important because it would reduce HIV infection without necessarily talking about AIDS and, thus, students would be willing to listen. Another example a student gave was to teach girls to have more self-confidence so they could be strong enough to say no to sex or to insist on the use of condoms. Here again, the participants stated that the focus should not be on the topic of AIDS but on building self-esteem. HIV prevention will come naturally after females are strong enough to say no to unsafe sexual intercourse.

Male participants also agreed with the proposal of 'indirect education'. They mostly stated that they wanted education to be more informal and entertaining. They particularly wanted to see it geared toward their interests. Aman stated, "We should be educated with things that we like and enjoy. Me, I love movies, so if they can incorporate AIDS education in my movies, that will be perfect." Other means the male participants mentioned was the use of theatre, dance, or sports. Solomon added, "We are more focused on things that we already appreciate, so schools should use this; they must focus on entertainment as a means to teach us about AIDS, but they shouldn't talk about the disease itself, at least not directly."

\section{Theme 2: Gap Between Teachers'And Students' Preference}

One issue all students repeatedly mentioned was in reference to the gap between what students wanted to learn and what the educators taught them. This specifically happens when it is school teachers who give the HIV/AIDS education (rather than guests from different associations).

Teachers only teach what they are comfortable with, but not necessarily what we need. For example, they don 't tell us to use condoms; they just say abstinence, abstinence, abstinence! They think that if they tell us to use condoms, we will interpret it as go and have sex as much as we want, said Solomon.

Lily stated this about the gap that exists:

Our generation is into having fun, enjoying life and so on ... [long pause]. So telling this generation not to have sex is not helping, because this type of talk does not attract us at all and we don't listen. So, it's important that HIV/AIDS educators give lessons that are tailored to our generation and our needs. They have to be more openminded... In my school, there is no information about condoms at all. In fact, even the logo of our anti-AIDS club is the image of abstinence.

Another issue participants mentioned was that their teachers do not use the correct language to educate students about AIDS. Students dread the fact that teachers - especially older teachers - used warnings and fear to tell students how terrible HIV/AIDS is. "Many teachers are too rough and use harsh words to make us afraid of the disease - to the point that some people who learn that they have AIDS will commit suicide", said Biniam (male). All 
participants agreed that although AIDS is a serious disease, the way to inform students should not be in a scary manner but rather in a hopeful way. "Fear will only bring anger. Clear and open explanations are better ways to go about educating", said Tuti (male). "They give us warnings instead of advice. That's the wrong method", stated Meti (female).

\section{Theme 3: Student-To-Student Education}

When asked which type of HIV/AIDS education students preferred from all the ones they have received at school, participants unanimously answered that it was the ones given by students themselves. Indeed, students do run one form of HIV/AIDS education given in Ethiopian schools. For example, in anti-AIDS clubs, students are trained by NGO staff and are asked to disseminate what they have learned to other students. The other methods include school teachers who give HIV/AIDS lectures (mostly in ethics or biology class) and outside organizations that conduct outreach in various schools. Anti-AIDS clubs are more popular than the other two forms of education, but there are still some limitations that students identified. Lemlem, a girl who has been selected as one of the students to train other students in her school, said:

Since we have more knowledge and experience in the subject, we can properly circulate the message, and students listen to us better than they will listen to teachers . . but unfortunately, there are far more girls involved than boys in anti-AIDS clubs. Boys are not very attracted to it, so there needs to be some type of incentive for them to participate too.

Yes, added Lily, "Students are like us, so we can ask them whatever question we want, so it's better when they teach us, rather than our teachers. But because adults train them, sometimes it seems that they simply repeat what they were told. A male participant - Mekonin - said:

Definitely, anti-AIDS clubs are much better than our teachers' lessons. I want to see AIDS clubs more involved though - not to only be active once a year on AIDS Day or when there is a particular event. We can get infected any day, so AIDS clubs should be there to support us every day.

\section{Theme 4: Role Of Parents}

Although the interview questions were solely about school-based education, participants wanted to express their thoughts about what parents' roles should entail. Culturally, it is not common for Ethiopian parents to talk about AIDS or sex to their children; however, all participants stated they wanted to see that change. "Technically, it should not even be the school's responsibility to teach us about AIDS, but our parents'. If we grew up in an environment where AIDS was openly communicated, I think we'd behave in a much safer manner", stated Nuna (female). "I completely agree", said Lily, and she added after a pause:

Parents have to be up-to-date with what is happening and start communicating with us. It is not in our culture yet to have parents talk to their kids about sex, but that is what is killing us, so this has to change. Maybe parents need to be educated on how to talk to us about AIDS.

The idea of educating parents was also expressed in the boys' group. Tesfaye stated, "Parents need to be educated on AIDS issues as much as us, if not more. Media and schools are mostly focusing on educating the youth, but nobody is teaching older people. How can they help us if they don't know?", to which Tuti added, "I agree with you, Tesfaye. If my parents ever saw me with a condom in my hand or in my pocket, they would freak out [everyone laughs], seriously, it would be the end for me".

\section{Gender Difference}

Theme 5. A: The Media Technique (Male Participants)

Both females and males agreed that school-based HIV/AIDS education programs had several limitations (gap between teachers' and students' preference, saturation issue, and lack of indirect education). They proposed 
several solutions to the issue as explained in the above sections (themes 1 through 4). Male participants had one more suggestion to add - called 'the media technique'. The media in Ethiopia is very active in disseminating messages about HIV prevention and treatment for AIDS. Through the use of entertainment, they have been able to reach a large number of youth in a way that is 'attractive' as opposed to the 'boring' in-school AIDS programs. Abraham (15 years old) stated, "Media is doing an excellent job. Sometimes the words they use might seem aggressive or too direct, but that's the language we use among us youth, so it's okay. It is our reality", to which Aman added, "Yes, media tells us things exactly the way they are - no hiding, no secrets. They use the right language and are not shy to talk openly about sex."

Despite all the efforts and money that is being spent on school-based AIDS education, all the male participants stated that they preferred the media delivering the messages and received the majority of their own AIDS knowledge through media. Mekonin announced:

To be honest, most of what I learned about AIDS was through media and not school. Media has found exactly what we want [long pause]. They first get our attention by using drama, soap opera, radio shows, or music. Then they incorporate an AIDS issue. If schools could somehow adopt this technique, I'm sure they'd do a much better job, and we'd listen more.

All male participants agreed with these statements. HIV/AIDS media education was open, clear, and interesting. School-based education programs were not. Participants showed great enthusiasm about media education and hoped that schools would adopt these methods. The males believed that in-school AIDS education is extremely important and should continue, but it needs considerable improvement. They wanted to see more 'interesting and entertaining' ways of teaching about AIDS and not to have formal classes. If this was to be incorporated, they were willing to participate in any school-based education on AIDS.

\section{Theme 5. B: Drug And Alcohol Issues (Female Participants)}

Unlike the male participants who focused on a technique to improve in-school HIV/AIDS education (incorporating the media technique), the girls believed that the entire way of educating needed to be modified. Female participants believed that the issue was not just educational but governmental. They believed the biggest issue was the easy access to drugs and alcohol for youth. "No matter what education we get at school, if students are high or drunk, they won't remember it", stated Mistere. Indeed, in Ethiopia, youth are able to buy alcohol at any age. The same goes for prescription drugs, as long as the child has a prescription-weather it is under his/her name or not - he/she is able to buy the medicine.

One drug easily accessible at any store is khat, a plant and stimulant known to cause excitement. Khat is legal in Ethiopia, despite the fact that the World Health Organization (WHO) classifies it as a 'drug of abuse.' Hence, people have easy access to it. Nuna stated:

I think our generation is more into drinking and abusing drugs than our parents were at our age. The law needs to be stricter and not allow underage people to buy alcohol or drugs. Under the influence, teens do stupid things at school and get infected. There is not enough HIV/AIDS education that can overcome the issue of drugs and alcohol . .. Also, teachers should educate us about the problems that come from alcohol and drug abuse, instead of telling us the same thing about HIV/AIDS again and again.

All female participants shared their feelings about drug and alcohol issue. They blamed 'day parties' that were supposed to be for teenagers but where older people sometimes came and sold drugs. Some students also bought alcohol from outside sources and brought it to the parties. Regarding nightclubs that are restricted to individuals older than 18, participants stated that they frequently were able to go in as long as they knew the bouncer or looked old enough. "That's very dangerous. There should be a system in which young teens are not allowed to go in no matter what, or if they go in, then they should not be allowed to drink", stated Lamrot. 


\section{DISCUSSION}

HIV/AIDS education in schools is critically important in Ethiopia. Students participate in them and are able to build HIV/AIDS awareness. Unfortunately, most of the AIDS programs available in schools are becoming less and less popular among students. All participants in this research project disapproved of the way many of their teachers presented content about AIDS because there was a gap between the materials offered and the students' needs. Participants explained that the lessons were too monotonous, boring, and lacked innovation. In addition, some teachers seemed uncomfortable talking about sex freely, so students refrained from asking any questions. This links to what Kinsman et al. (1999) and Oshi et al. (2005) stated about how teachers were unwilling to talk about sexuality. This is the reason why students found the education to be superficial. However, the Ethiopian media seem to be highly effective because students are fond of entertainment education. Hence, participants stated that they receive most of their information about AIDS from television, radio, or newspapers.

An important finding to highlight is that students overwhelmingly supported indirect education. They hoped to see a way implemented in which educators could teach about the means to reduce HIV infection, without talking about the disease itself. Teaching valuable social skills such as self-confidence and self-awareness, openly talking about issues of drug and alcohol, or using art and culture to disseminate AIDS message were a few suggestions offered. Additionally, students preferred to be educated by their peers or outside NGO staff rather than by teachers.

The fact that youth are asking for stricter measures and protection from drugs and alcohol is an indication of their motivation to stay safe. Educators and parents need to listen to this and foster that motivation. In fact, the majority of the youth believed it was the parents' role to educate them about AIDS. This is another indication that youth are asking for support. Perhaps workshops could be designed to assist parents in talking about AIDS, and even drugs and alcohol issues.

The implication of these findings is that school-based HIV/AIDS education in Ethiopia-as important as it is - needs to improve. The fact that it is becoming less popular among students should alarm the Ethiopian health care and education system. Large amount of funds and time are devoted to provide these HIV/AIDS programs. If students do not appreciate them and their behaviour concerning safer sex practices does not rapidly change, then newly designed and effective AIDS education programs must be developed and implemented.

\section{LIMITATION}

It is crucial to remember that this research was conducted in one particular city - Addis Ababa. The findings gleaned from this research might not be transferable to other urban regions of Ethiopia. In addition, this research comprises the opinions of 15 high school students, which cannot be representative of the entire population of youths in Addis Ababa. However, due to the maximal variation sampling method used, it is fair to assume that participants came from all different corners of the city. Finally, the research method used was focus groups. A limitation of conducting focus groups such as these is that participants can feed off each other and thus be influenced to answer in a certain way. Conducting one-on-one interviews might bring about different results. Nevertheless, for this particular project, it was important that students felt at ease, and thus a focus group that included participants their own age was appropriate, rather than a formal interview with an adult. Focus group offers a means for interaction to take place, which stimulates discussion. In both groups (male and female), the conversations provided great dynamics that generated new and unexpected ideas about the topic - parent's involvement, the media aspect, and drugs and alcohol issue, to name a few.

\section{FURTHER RESEARCH}

In exploring how the findings can inform future researchers, there are three directions that the author finds essential to study. First, students seemed to believe that teachers were not comfortable to openly discuss sex, which made the HIV/AIDS education weak. It would be interesting and helpful to design research that examines the role of the educators. Why are they sometimes unwilling to teach AIDS in their classrooms? What type of feedback do educators receive from their students or other staff members when teaching about AIDS? Second, participants showed high interest in having their parents more involved in educating them about AIDS at a young age. Perhaps, further 
research could study the cultural issues that deter parents from openly speaking to their children about AIDS. In particular, looking at parents' experience and perceptions would be extremely significant and revealing. Last, regarding the drug and alcohol problem brought up by the female participants, further research needs to be conducted to understand the depth of this issue and to determine whether possible solutions could be introduced. What are the drugs students have access to and how exactly do they have access to these drugs? What can government officials do to solve this growing problem? This drug and alcohol matter does not only affect the AIDS issue but can also cause other social and economic hindrances to the country. It is therefore worth studying this critical issue immediately.

\section{CONCLUSION}

The primary purpose of this research was to explore how Ethiopian high school students experienced the HIV/AIDS education programs offered in their schools. It was found that students understood the importance of HIV/AIDS education but believed that it had several limitations. For one, the participants were displeased that the education they received in class was similar from year to year. It lacked novelty and was often boring. When the education was offered by peers (student-to-student education), they felt it was much more interesting but still believed that there was room for improvement. The solutions they proposed included indirect education, to have teachers that understood their needs better, and to involve parents in their education about HIV/AIDS.

The second objective of this project was to examine whether gender differences existed in the way HIV/AIDS education was perceived by students. For the most part, both male and female participants agreed on the main issues hindering HIV/AIDS education - it lacks innovation. Both groups proposed similar solutions when it came to parental involvement and indirect education. However, the groups differed in one particular aspect - Males proposed that a media technique be adopted by schools (incorporating entertainment education) and females, however, wanted to see modifications, not only in the way the education was presented at school, but also in policies concerning the easy access to drugs and alcohol.

The gap that exists between HIV/AIDS awareness and behavioural change is a pressing matter that continually needs to be studied. This project has brought interesting and essential findings that Ethiopian teachers, parents, and HIV/AIDS prevention researchers can learn from and continue to study further. It is clear that more needs to be done in Ethiopia concerning effective HIV prevention strategies for youth and to considerably reduce the rate of new infections.

\section{ACKNOWLEDGMENTS}

To all the participants of this study - the gatekeeper, the social worker and the assistants that were involved in this research and to the member checking personnel and the external auditor who reviewed the results before the final submission - thank you!

\section{AUTHOR INFORMATION}

Mariam Sambe has been involved in the field of education for 15 years working in all levels from preschool to university. Her experience as an educator and researcher has led her to manage several educational programs in Ethiopia, France, Canada and the United States. Currently, she is a doctoral student in Education and the focus of her research is on HIV/AIDS education in African institutions. Outside of academia, Mariam dedicates her life to humanitarian organizations like the Red Cross, Shriners hospital and varied orphanages. She is the co-founder of Welfare by Teenagers and Sponsor Ethiopia - organizations that support disadvantaged children with needs such as shelter, food, clothing and education. Email: mar_fara@education.concordia.ca.

\section{REFERENCES}

1. Aklilu, M., Mesele, T., Tsegaye, A., Biru, T., Mariam, D. H., van Benthem, B., Coutinho, R., Rinke de Wit, T., \& Fontanet, A. (2001). Factors associated with HIV-1 infection among sex workers of Addis Ababa, Ethiopia. AIDS 15, no. 1: 87-96.

2. Alene, G. D., Wheeler, J. G., \& Grosskurth, H. H. (2004). Adolescent reproductive health and awareness of 
HIV among rural high school students, North Western Ethiopia. AIDS Care, 16(1), 57-68.

3. Federal Ministry of Health. (2007). Single Point HIV Prevalence Estimate. Federal Ministry of Health, 2007 Addis Ababa, Ethiopia.

4. Fetene, G., \& Dimitriadis, G. (2010). Globalization, public policy, and 'knowledge gap': Ethiopian youth and the HIV/AIDS pandemic. Journal of Education Policy, 25(4), 425-441.

5. HAPCO (National HIV/AIDS Prevention and Control Office). (2007). Multisectoral plan of action for universal access to HIV prevention, treatment, care and support in Ethiopia 2007-2010. HAPCO, Addis Ababa, Ethiopia.

6. HAPCO (National HIV/AIDS Prevention and Control Office). (2008). Report on progress towards implementation of the UN declaration of commitment on HIV/AIDS. Federal HIV/AIDS Prevention and Control Office. Addis Ababa, Ethiopia.

7. Hyde, K. A. L., Ekatan, A., Kiage, P., \& Barasa, C. (2001). The impact of HIV/AIDS on formal schooling in Uganda. Retrieved on November 1, 2012 from http://hivaidsclearinghouse.unesco.org/search/resources/impact_formal_schooling_uganda.pdf.

8. HyperRESEARCH. (2013). Computer Software, ResearchWare, Inc., Version 3.5.2. $<\mathrm{http} / / / \mathrm{www} \cdot$ researchware.com/>.

9. Jacob, W., Mosman, S. S., Hite, S. J., Morisky, D. E., \& Nsubuga, Y. K. (2007). Evaluating HIV/AIDS education programmes in Ugandan secondary schools. Development In Practice, 17(1), 114-123.

10. Jacob, W., Morisky, D. E., Hite, S. J., \& Nsubuga, Y. K. (2006). Evaluation of HIV/AIDS education programs in Uganda. In Morisky, D. E., Jacob, W., Nsubuga, Y. K., \& Hite, S. J. (Eds). Overcoming AIDS: Lessons learned from Uganda, pp.63-82. Greenwich, CT: Information Age.

11. Jacob, W., Shaw, S. A., Morisky, D. E., Hite, S. J., \& Nsubuga, Y. K. (2007). HIV/AIDS Education: What African Youth Say Is Effective. Families in Society, 88(1), 104-114.

12. Kaaya, S. F., Mukoma, W., Flisher, A. J., \& Klepp, K. I. (2002). School-based sexual health intervention in Sub-Saharan Africa: A review. Social Dynamics, 28, 64-88.

13. Kelly, M. J. (2000). Planning for education in the context of HIV/AIDS (vol. 66). Paris: UNESCO: International Institute for Educational Planning.

14. Kinsman J., Harrison S., Kengeya-Kayondo J., Kanyesigye E., Musoke S., \& Whitworth J. (1999). Implementation of a comprehensive AIDS education programme for schools in Masaka District, Uganda. AIDS Care, 11(5), 591-601.

15. Kloos, H., \& Haile Mariam, D. (2000). Community-based organizations and poverty alleviation programs in HIV/AIDS prevention and control in Ethiopia: A preliminary survey. Northeast African Studies 7(2)13-33.

16. Mathews, C. C., Boon, H. H., Flisher, A. J., \& Schaalma, H. P. (2006). Factors associated with teachers' implementation of HIV/AIDS education in secondary schools in Cape Town, South Africa. AIDS Care, 18(4), 388-397.

17. Molla, M., Emmelin, M., Berhane, Y., \& Lindtjørn, B. (2009). Readiness of youth in rural Ethiopia to seek health services for sexually transmitted infections. African Journal of AIDS Research (AJAR), 8(2), 135-146.

18. Oshi, D. C., Nakalema, S., \& Oshi, L. L. (2005). Cultural and social aspects of HIV/AIDS sex education in secondary schools in Nigeria. Journal of Biosocial Science, 37(2), 175-183.

19. Sambe, M. (2009). HIV/AIDS in urban Ethiopia: Motivation and thought process of the youth community regarding condom use. Hawaii Pacific University. ProQuest Dissertations and Theses. (ProQuest document ID: 931479432).

20. Tamene, W., \& Fantahun, M. (2007). Fertility desire and family-planning demand among HIV-positive women and men undergoing antiretroviral treatment in Addis Ababa, Ethiopia. African Journal of AIDS Research (AJAR), 6(3), 223-227.

21. UNAIDS. (2008). Regional support team for Eastern and Southern Africa: Country profile. Joint United Nations Programme on HIV/AIDS.

22. UNAIDS. (2009). AIDS Epidemic update. The Joint United Nations Programme on HIV/AIDS (UNAIDS) and World Health Organization (WHO).1.1-100. 


\section{NOTES}

